\title{
Pola Penentu Keadaan Status Gizi Balita Dalam Association Rule Mining Berdasarkan Teknik Antropometri
}

\author{
${ }^{1}$ Kurniadi Irawan, ${ }^{2}$ Hendra Kurniawan, ${ }^{3}$ Wahyu Sindu Prasetya \\ ${ }^{1,2,3}$ STMIK Pontianak; Jln. Merdeka Barat No. 372 Pontianak, (0561)73555/(0561)737777 \\ e-mail: ${ }^{1}$ kurniadiiawan3@gmail.com, ${ }^{2}$ raafi.hendra@gmail.com, \\ wahyusinduprasetya@gmail.com
}

\begin{abstract}
Abstrak
Posyandu merupakan fasilitas kesehatan yang merupakan kegiatan swadaya dari masyarakat dibidang kesehatan. Dimana dalam kegiatan tersebut terdapat aktifitas pengukuran keadaan status gizi balita, pengukuran tersebut dilakukan menggunakan teknik Antropometri. Teknik antropometri merupakan pengukuran yang dilakukan untuk mengetahui ukuran fisik seorang anak dengan menggunakan alat ukur tertentu seperti timbangan dan pita ukur. Situasi saat ini, proses pengumpulan data perkembangan riwayat gizi balita pada posyandu atau puskesmas dikerjakan secara manual oleh petugas dengan mencatat segala data yang terkait dengan perkembangan gizi pada balita itu sendiri. Diperlukan sebuah data mining untuk melihat hubungan antara indeks antropometri dalam menentukan status gizi balita, dan dengan data mining diharapkan memberikan suatu kontribusi dalam pengambilan keputusan dari suatu permasalahan. Algoritma apriori adalah algoritma pengambilan data dengan aturan assosiatif (Association rule) untuk menentukan hubungan assosiatif suatu kombinasi item. Association Rule yang dimaksud dilakukan melalui mekanisme penghitungan Support dan confidence dari suatu hubungan item Hasil penelitian ini adalah suatu aplikasi data minng yang membantu petugas posyandu melihat pola dari keadaan penentu status gizi balita.
\end{abstract}

Kata Kunci : Status Gizi, Data Mining, Association Rule, Apriori, Antropometri

\begin{abstract}
Posyandu is a health facility which is self-supporting activities of community health. Where in these activities are activities of a state measure nutritional status of children, the measurement is performed using anthropometry techniques. Mechanical anthropometric measurement is performed to determine the physical size of a child by using a certain measuring devices such as scales and measuring tape. The current situation, the process of collecting data on the development of infant nutritional history Posyandu or Puskesmas is done manually by the officer to record all data associated with the development of nutrition in infants themselves. Needed a data mining to look at the relationship between anthropometric indices in determining the nutritional status of children, and with data mining is expected to give a contribution in the decision of problem.Apriori Algorithm is algorithms of retrieval data with the rules assosiative (Association rule) to determine a combination of associative relationship item. Association Rule is done through a calculation mechanism Support and confidence of a relationship item is a result of this research minng data applications that help officers posyandu see the pattern of the deciding state nutritional status of children.
\end{abstract}

Keywords: Nutritional Status, Data Mining, Association Rule, Apriori, anthropometry 


\section{PENDAHULUAN}

Anak usia dibawah lima tahun (Balita) pada dasarnya masih belum bisa memilah konsumsi makanan yang baik untuk dirinya sendiri yang rentan terhadap masalah kesehatan dan gizi, khususnya kurangnya pengetahuan peranan orang tua dalam menjaga keadaan status gizi balita sehingga perlu perhatian serius dari instansi terkait. Penilaian Status gizi dapat ditentukan melalui pemeriksaan secara antropometri. Antropometri merupakan cara penentuan status gizi yang paling mudah dan murah. Pengukuran antropometri adalah pengukuran yang digunakan untuk menentukan keadaan gizi balita. Agar memperoleh hasil yang tepat, diberikan suatu patokan sebagai pedoman. Z-Skor merupakan index antropometri yang digunakan secara internasioal untuk penentuan status gizi dan pertumbuhan, yang diekspresikan sebagai satuan standar deviasi (SD) populasi. Z-Skor digunakan untuk menghitung status gizi secara antropometri pada berat badan terhadap umur $(\mathrm{BB} / \mathrm{U})$, tinggi badan terhadap umur $(\mathrm{TB} / \mathrm{U})$, berat badan terhadap tinggi badan (BB/TB). Tabel Untuk BB/U, TB/U, dan BB/TB.

Meningkatnya jumlah data keadaan status gizi balita yang didapat, membuat data mining sangat diperlukan untuk mengekstraksi pengetahuan secara otomatis dari berbagai data yang diperoleh, dengan cara mencari pola-pola yang terkandung di dalam data tersebut. Pemanfaatan data mining sudah banyak diterapkan dalam suatu instansi, dalam pemanfaatannya, data mining dapat digunakan dalam menangani meledaknya volume data, bagaimana menyimpannya, mengekstraknya dan dapat menghasilkan informasi yang dibutuhkan. Informasi yang dihasilkan menjadi aset untuk meningkatkan daya saing suatu institusi. Selain itu data mining juga berperan dalam menghasilkan suatu informasi untuk pengambilan keputusan.

Penerapan Association Rule pada Data Mining, dapat dilihat pada penting tidaknya suatu Association Rule dengan menggunakan dua parameter, yaitu support (nilai penunjang) atau persentase kombinasi item tersebut dalam database dan confidence (nilai kepastian) yaitu kuatnya hubungan antar item. Association Rule pada data mining, menunjukkan sebuah teknik yang menjanjikan untuk menemukan pola yang tersembunyi di dalam tumpukan data .

\section{METODE PENELITIAN}

Dalam penelitian ini penulis menggunakan metode penelitian Research \& Development (R\&D). Metode penelitian yang digunakan untuk menghasilkan produk tertentu, dan menguji keefektifan produk tersebut". Produk tersebut tidak selalu berbentuk benda atau perangkat keras (hardware), seperti buku, alat tulis, dan alat pembelajaran lainnya. Akan tetapi dapat pula dalam bentuk perangkat lunak (software) seperti program pengolah data, pembelajaran di kelas, perpustakaan atau laboratorium,atau model-model pendidikan pembelajaran pelatihan, bimbingan, evaluasi, manajeman dan lain sebagainya[1].

\subsection{Metode Pengumpulan Data}

Adapun jenis data yang digunakan penulis dalam penelitian ini yaitu, sebagai berikut:

a.Data primer

merupakan sumber data yang diperoleh secara langsung dari sumber asli atau pihak pertama. Data primer secara khusus dikumpulkan oleh peneliti untuk menjawab pertanyaan riset atau penelitian. Data primer dapat berupa pendapat subjek riset (orang) baik secara individu maupun kelompok, hasil observasi terhadap suatu benda (fisik), kejadian, atau kegiatan, dan hasil pengujian. Sumber perimer adalah sumber data yang langsung memberikan data kepada pengumpul data[1].

b.Data sekunder

Data sekunder adalah data yang tidak didapatkan secara langsung dari objek penelitian, melainkan sumber data yang diperoleh peneliti secara tidak langsung melalui media perantara. Data sekunder pada umumnya berupa bukti, catatan, atau laporan historis yang telah tersusun dalam arsip, baik yang dipublikasikan dan yang tidak dipublikasikan. Data sekunder antaralain disajikan dalam bentuk tabel-tabel, diagram- 
diagram, atau mengenai topik penelitian. Sumber data yang tidak langsung memberikan data kepada pengumpul data, misalnya lewat orang lain atau lewat dokumen[1].

\subsection{Teknik Pengumpulan Data}

Teknik pengumpulan data adalah cara-cara yang dilakukan untuk mencari, mengumpulkan dan memperoleh data untuk digunakan dalam melakukan penelitian, baik itu data yang diperoleh dengan servei langsung maupun dengan penggalian informasi. Teknik pengumpulan data merupakan langkah yang paling strategis dalam penelitian, karena tujuan utama dari penelitian adalah mendapatkan data[1]. Untuk memperoleh data dan informasi dalam penelitian ini, penulis menggunakan teknik pengambilan data sebagai berikut :

a. wawancara

Dapat dilakukan oleh pewawancara adalah menarik minat responden agar berseia menjawab pertanyaan yang diajukan[2]. Penulis melakukan wawancara untuk mendapatkan informasi dengan mengajukan beberapa pertanyaan secara langsung atau tatap muka. Penulis menggunakan meode wawancara tidak terstruktur dimana wawancara dilakukan dengan keadaan spontan tanpa dipersiapkan pertanyaan dahulu.

b. Studi Dokumentasi

Teknik dokumentasi berupa studi keputusan dan kajian dari buku-buku, jurnal-jurnal pendukung (hardcopy dan software), literatur dari internet dan sejumlah dokmen mengenai data variabel yang perlukan.

c. Observasi

Pada penelitian ini observasi yang dilakukan dengan pengamatan langsung mengumpulkan data mengenai dokumentasi yang mengacu pada instrumen pengamatan yang berisi definisi-definisi dari item-item data. Melakukan kajian letretur yang berkaitan dengan penelitian yang dilakukan, pengumpulan data yang diperoleh dari sumber tertulis seperti: literatur artikel, berbagai websait, dan tulisan ilmiah yang dianggap terkait dan relevan dengan topik penelitian.

\subsection{Pengembangan Perangkat Lunak RAD}

Penulis mengunakan metode perancangan RAD (Rapid Application Developement) karena peroses perkembangan perangkat lunak ini menekankan pada siklus perkembangan yang singkat dan pemanfaatan fungsi yang telah ada sebelumnya. Adapun langka-langkah yang dilakukan penulis yaitu: RAD adalah suatu pendekatan berorientasi objek terhadap pengembangan sistem yang mencakup suatu metode pengembangan serta perangkat-perangkat lunak[3].

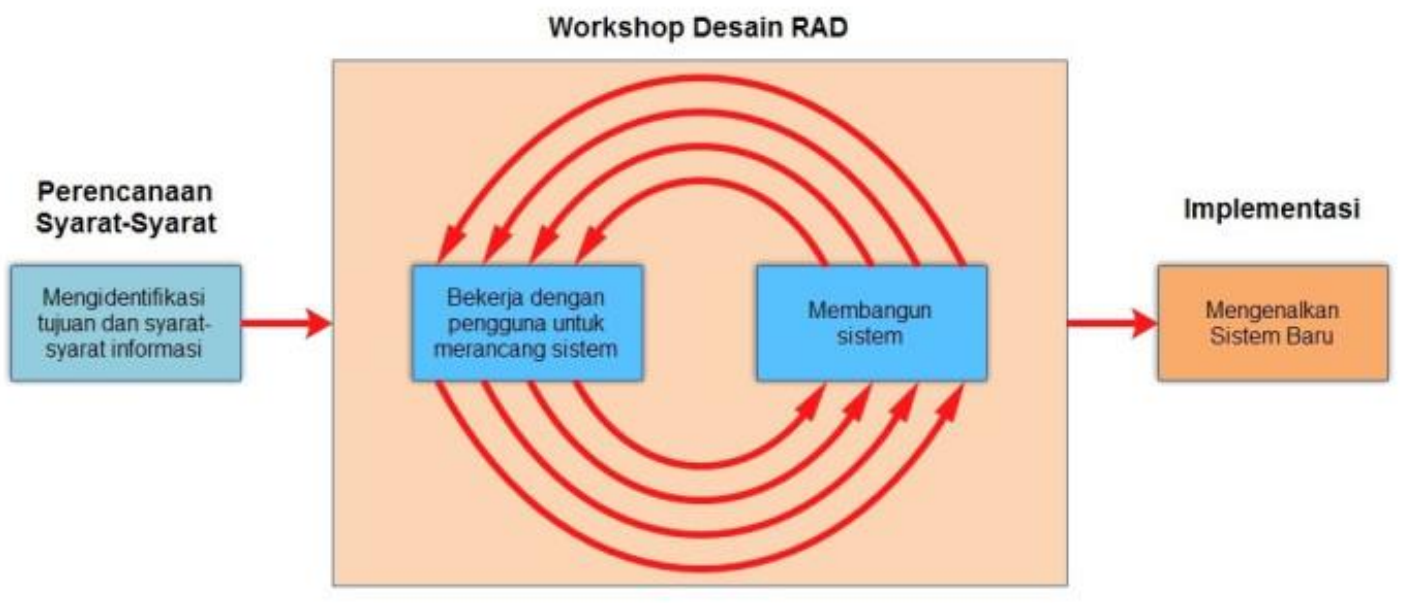

Gambar 2.1 Siklus RAD

(Sumber: Borg.W.R, 2015) 


\subsection{Alat Pengembangan Sistem Perangkat Lunak}

2.4.1 Flowchart

Flowchart adalah adalah suatu bagan dengan simbol-simbol tertentu yang menggambarkan urutan proses secara mendetail dan hubungan antara suatu proses (instruksi) dengan proses lainnya dalam suatu program.

\subsubsection{Algoritma}

Algoritma adalah urutan langkah-langkah logis penyelesaian masalah yang disusun secara sistematis dan logis". Kata logis merupakan kata kunci dalam algoritma. Langkahlangkah dalam algoritma harus logis dan harus dapat ditentukan bernilai salah atau benar. Dalam beberapa konteks, algoritma adalah spesifikasi urutan langkah untuk melakukan pekerjaan tertentu. Pertimbangan dalam pemilihan algoritma adalah, pertama, algoritma haruslah benar. Artinya algoritma akan memberikan keluaran yang dikehendaki dari sejumlah masukan yang diberikan. Tidak peduli sebagus apapun algoritma, kalau memberikan keluaran yang salah, pastilah algoritma tersebut bukanlah algoritma yang baik.

\subsubsection{UML (Unified Modelling Language)}

Unified Modeling Language (UML) adalah bahasa pemodelan secara grafis untuk menspesifikasikan, menvisualisasikan, membangun, dan mendokumentasikan seluruh rancangan sistem perangkat lunak. Penggunaan model ini bertujuan untuk mengidentifikasikan bagian-bagian yang termasuk dalam lingkup sistem yang dibahas dan bagaimana hubungan antara sistem dengan subsistem maupun sistem lain di luarnya. Selain itu UML menggunakan class dan operation dalam konsep dasarnya, maka ia lebih cocok untuk penulisan[4],[5].

\subsubsection{Sequence Diagram}

Sequence Diagram digunakan untuk menggambarkan scenario atau rangkaian langkahlangkah yang dilakukan sebagai suatu respon dari kejadian untuk menghasilkan output tertentu.

\subsubsection{Activity Diagram}

Menggambarkan rangkaian aliran dari aktivitas, digunakan untuk mendeskripsikan aktifitas yang dibentuk dalam suatu operasi sehingga dapat juga digunakan untuk aktifitas lainnya seperti use case atau interaksi berikut merupakan gambaran dari activity steganografi 2.4.3.3 Use Case Diagram

Use case diagram merupakan permodelan untuk behavior sistem informasi yang dibuat dan mendeskripsikan sebuah interaksi antara satu atau lebih aktor dengan sistem informasi yang akan dibuat serta digunakan untuk mengetahui fungsi apa saja yang ada didalam sebuah sistem informasi dan siapa saja yang berhak menggunakan[4],[5].

\section{HASIL DAN PEMBAHASAN}

\subsection{Pengujian Perhitungan Association Rule Menggunakan Algoritma Apriori[7]}

Pada tahap ini perhitungan dilakukan dengan menggunakan algoritma Apriori yang terdapat dalam, metode Association rule, dimana algoritma apriori mencari nilai support dan confidence, berikut merupakan tahapan perhitungannya. Kita mempunyai table kondisi status gizi dibawah ini, yang ingin dijadikan item set.

Tabel 1. Tabel kondisi status gizi

\begin{tabular}{|l|l|}
\hline ID - Transaksi & Kondisi \\
\hline 1 & BB/U kurang, TB/U kurang, BB/TB kurang \\
\hline 2 & BB/U nomal, TB/U normal, BB/TB normal \\
\hline 3 & BB/U lebih, TB/U lebih, BB/TB lebih \\
\hline
\end{tabular}


Tabel 2. TabelDaftar itemset

\begin{tabular}{|l|}
\hline BB/U kurang \\
\hline TB/U kurang \\
\hline BB/TB kurang \\
\hline BB/U normal \\
\hline TB/U normal \\
\hline BB/TB normal \\
\hline BB/U lebih \\
\hline TB/U lebih \\
\hline BB/TB lebih \\
\hline
\end{tabular}

Support dari setiap kandidat frequent item set didapat dengan menscan database, dimana di peroleh berbagai kondisi dari setiap item set, kondisi yang diperoleh ialah sebagai berikut :

$\{\mathrm{BB} / \mathrm{U}$ Kurang-TB/U Kurang, BB/U Kurang-BB/TBkurang, BB/U kurang-BB/U-Normal, TB/U Kurang-TB/U Normal, BB/U Kurang-BB/TB Normal, BB/U kurang- BB/U lebih, BB/U kurang-TB/U lebih, BB/U kurang-BB/TB lebih, TB/U kurang-BB/TB kurang, TB/U kurangBB/U normal, TB/U kurang-TB/U normal, TB/U kurang-BB/TB normal, TB/U Kurang-BB/U lebih, TB/U kurang-TB/U lebih, TB/U Kurang-BB/TB lebih, BB/TB Kurang-BB/U normal, $\mathrm{BB} / \mathrm{TB}$ kurang-TB/U normal, BB/TB kurang-BB/TB normal, BB/TB kurang-BB/U Lebih, BB/TB Kurang-BB/U lebih, BB/TB Kurang-BB/TB lebih, BB/U normal- TB/U normal, BB/U normal-BB/TB normal, BB/U normal- BB/U lebih, BB/U normal-TB/U lebih, BB/U Normal$\mathrm{BB} / \mathrm{TB}$ lebih, $\mathrm{TB} / \mathrm{U}$ normal-BB/TB normal, $\mathrm{TB} / \mathrm{U}$ normal-BB/U lebih, TB/U Normal-TB/U lebih, TB/U Normal-BB/TB lebih, BB/TB normal-BB/U lebih, BB/TB normal-TB/U lebih, BB/TB Normal-BB/TB Lebih, BB/U lebih-TB/U lebih, BB/U lebih-BB/TB lebih, TB/U lebih$\mathrm{BB} / \mathrm{TB}$ lebih\}

Table terjadinya transaksi antara kondisi diatas.

$\mathrm{T}=$ Transaksi

$\mathrm{F}=$ Frequensi

$\mathrm{P}=$ Kondisi yang terjadi bersamaan

$\mathrm{S}=$ Tidak ada kondisi yang terjadi bersamaan

Dari setiap kondisi yang terjadi, terdapat tiga table yang memiliki nilai frequent item set yang sering muncul yaitu : 
Tabel 3.

Kondisi BB/TB

\begin{tabular}{|c|c|c|c|}
\hline $\mathbf{T}$ & $\begin{array}{l}\text { BB/TB } \\
\text { Kurang }\end{array}$ & $\begin{array}{l}\text { BB/U } \\
\text { Normal }\end{array}$ & $\mathbf{F}$ \\
\hline 1 & 1 & 0 & $\mathrm{~S}$ \\
\hline 2 & 1 & 1 & $\mathrm{P}$ \\
\hline 3 & 1 & 0 & $\mathrm{~S}$ \\
\hline 4 & 1 & 0 & $\mathrm{~S}$ \\
\hline 5 & 1 & 0 & $\mathrm{~S}$ \\
\hline 6 & 1 & 1 & $P$ \\
\hline 7 & 1 & 0 & $\mathrm{~S}$ \\
\hline 8 & 1 & 1 & $\mathrm{P}$ \\
\hline 9 & 1 & 1 & $\mathrm{P}$ \\
\hline 10 & 1 & 0 & $\mathrm{~S}$ \\
\hline 11 & 1 & 0 & $\mathrm{~S}$ \\
\hline 12 & 1 & 1 & $P$ \\
\hline 13 & 1 & 1 & $\mathrm{P}$ \\
\hline 14 & 0 & 0 & $\mathrm{~S}$ \\
\hline 15 & 0 & 0 & $\mathrm{~S}$ \\
\hline 16 & 1 & 0 & $\mathrm{~S}$ \\
\hline 17 & 1 & 1 & $P$ \\
\hline 18 & 1 & 1 & $P$ \\
\hline 19 & 1 & 1 & $P$ \\
\hline 20 & 1 & 1 & $\mathrm{P}$ \\
\hline 21 & 0 & 0 & $\mathrm{~S}$ \\
\hline 22 & 1 & 1 & $\mathrm{P}$ \\
\hline 23 & 1 & 1 & $P$ \\
\hline 24 & 1 & 0 & $\mathrm{~S}$ \\
\hline \multirow[t]{2}{*}{25} & 1 & 1 & $\mathrm{P}$ \\
\hline & & $\sum$ & 13 \\
\hline
\end{tabular}

Tabel 4.

Tabel Kondisi BB/TB

Kurang TR/T Normal

\begin{tabular}{|c|c|c|c|c|c|c|c|}
\hline $\mathbf{T}$ & $\begin{array}{l}\text { BB/TB } \\
\text { Kurang }\end{array}$ & $\begin{array}{l}\text { TB/U } \\
\text { Normal }\end{array}$ & $\mathbf{F}$ & $\mathbf{T}$ & $\begin{array}{l}\text { BB/U } \\
\text { Normal }\end{array}$ & $\begin{array}{l}\text { TB/U } \\
\text { Normal }\end{array}$ & $\mathbf{F}$ \\
\hline 1 & 1 & 1 & $\mathrm{P}$ & 1 & 0 & 1 & $\mathrm{~S}$ \\
\hline 2 & 1 & 1 & $P$ & 2 & 1 & 1 & $\mathrm{P}$ \\
\hline 3 & 1 & 1 & $\mathrm{P}$ & 3 & 0 & 1 & $\mathrm{~S}$ \\
\hline 4 & 1 & 1 & $P$ & 4 & 0 & 1 & $\mathrm{~S}$ \\
\hline 5 & 1 & 0 & $\mathrm{~S}$ & 5 & 0 & 0 & $\mathrm{~S}$ \\
\hline 6 & 1 & 1 & $P$ & 6 & 1 & 1 & $P$ \\
\hline 7 & 1 & 1 & $\mathrm{P}$ & 7 & 0 & 1 & $\mathrm{~S}$ \\
\hline 8 & 1 & 1 & $P$ & 8 & 1 & 1 & $\mathrm{P}$ \\
\hline 9 & 1 & 0 & $\mathrm{~S}$ & 9 & 1 & 0 & $\mathrm{~S}$ \\
\hline 10 & 1 & 0 & $\mathrm{~S}$ & 10 & 0 & 0 & $\mathrm{~S}$ \\
\hline 11 & 1 & 1 & $P$ & 11 & 0 & 1 & $\mathrm{~S}$ \\
\hline 12 & 1 & 1 & $P$ & 12 & 1 & 1 & $\mathrm{P}$ \\
\hline 13 & 1 & 1 & $P$ & 13 & 1 & 1 & $\mathrm{P}$ \\
\hline 14 & 0 & 0 & $\mathrm{~S}$ & 14 & 0 & 0 & $\mathrm{~S}$ \\
\hline 15 & 0 & 1 & $\mathrm{~S}$ & 15 & 0 & 1 & $\mathrm{~S}$ \\
\hline 16 & 1 & 0 & $\mathrm{~S}$ & 16 & 0 & 0 & $\mathrm{~S}$ \\
\hline 17 & 1 & 1 & $\mathrm{P}$ & 17 & 1 & 1 & $\mathrm{P}$ \\
\hline 18 & 1 & 1 & $P$ & 18 & 1 & 1 & $\mathrm{P}$ \\
\hline 19 & 1 & 1 & $P$ & 19 & 1 & 1 & $\mathrm{P}$ \\
\hline 20 & 1 & 1 & $\mathrm{P}$ & 20 & 1 & 1 & $\mathrm{P}$ \\
\hline 21 & 0 & 1 & $\mathrm{~S}$ & 21 & 0 & 1 & $\mathrm{~S}$ \\
\hline 22 & 1 & 1 & $P$ & 22 & 1 & 1 & $\mathrm{P}$ \\
\hline 23 & 1 & 1 & $P$ & 23 & 1 & 1 & $\mathrm{P}$ \\
\hline 24 & 1 & 1 & $P$ & 24 & 0 & 1 & $\mathrm{~S}$ \\
\hline \multirow[t]{2}{*}{25} & 1 & 1 & $\mathrm{P}$ & 25 & 1 & 1 & $\mathrm{P}$ \\
\hline & & $\sum$ & 18 & & & $\sum$ & 12 \\
\hline
\end{tabular}

Dari ketiga table diatas, terdapat nilai frequent item set yang sering muncul dengan kondisi
1. BB/TB Kurang, BB/U Normal
$=13$
2. $B B / T B$ Kurang, $T B / U$ Normal
$=18$
3. $\mathrm{BB} / \mathrm{U}$ Normal, $\mathrm{TB} / \mathrm{U}$ Normal
$=12$

a. Pencarian Nilai Support

1. BB/TB Kurang, BB/U Normal

Support $=$ Jumlah

Kondisi BB/TB kurang-BB/U Normal X $100 \%$ Total Kondisi Status Gizi Balita

Support $=$

$\underline{13}$ $\mathrm{x}$ $100 \%$ 25

Support $=\quad \frac{13}{25} * \frac{1}{100}=\frac{13}{25} * \frac{100}{1}=\frac{130}{25}=52 \%$

2. BB/TB Kurang-TB/U Normal 


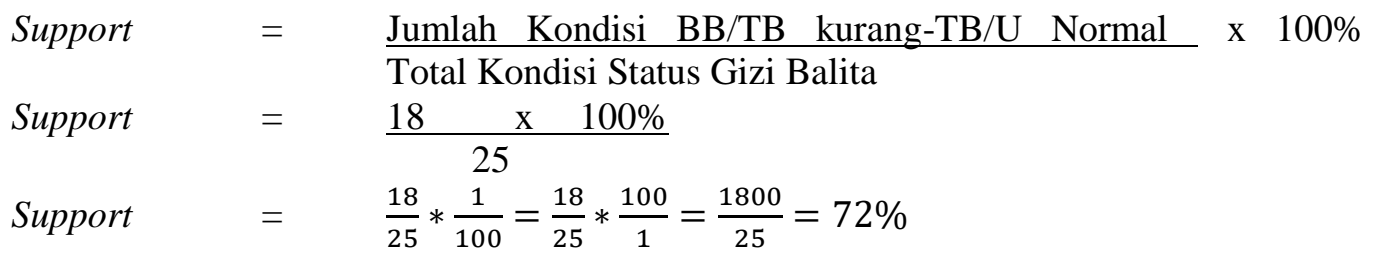

3. BB/U Normal TB/U Normal

$\begin{array}{lll}\text { Support } & = & \frac{\text { Jumlah Kondisi BB/UNormal-BB/U Normal }}{\text { Total Kondisi Status Gizi Balita }} \times 100 \% \\ \text { Support } & =\frac{12}{25} \times 100 \% \\ \text { Support } & =\frac{12}{25} * \frac{1}{100}=\frac{12}{25} * \frac{100}{1}=48 \%\end{array}$

b. Pencarian nilai confidence

1. BB/TB Kurang, BB/U Normal

$\begin{aligned} \text { Confidence } & =\frac{\text { Jumlah Kondisi BB/TB kurang,BB/U Normal }}{\text { Total Kondisi BB/TB kurang }} \times 100 \% \\ \text { Confidence } & =\frac{13}{22} * \frac{1}{100}=\frac{13}{22} * \frac{100}{1}=59 \%\end{aligned}$

2. Kondisi BB/TB Kurang, BB/U Normal

Confidence $=\underline{\text { Jumlah Kondisi } \mathrm{BB} / \mathrm{TB} \text { kurang, } \mathrm{TB} / \mathrm{U} \text { Normal }} \times 100 \%$

Confidence $=\frac{18}{22} * \frac{1}{100}=\frac{18}{22} * \frac{100}{1}=81 \%$

3. Kondisi BB/U Normal, TB/U Normal

Confidence $=\underline{\text { Jumlah Kondisi BB/U Normal,TB/U Normal }} \times 100 \%$ Total Kondisi BB/U Normal

Confidence $=\quad-\frac{12}{-13} * \frac{1}{100}=\frac{12}{13} * \frac{100}{1}=92 \%$

Tabel 6. Tabel Support dan Confidence

\begin{tabular}{|l|l|l|}
\hline Kondisi & Support & Confidence \\
\hline BB/TB Kurang-BB/U Normal & $52 \%$ & $59 \%$ \\
\hline BB/TB Kurang-TB/U Normal & $72 \%$ & $81 \%$ \\
\hline BB/U Normal-TB/U Normal & $48 \%$ & $92 \%$ \\
\hline
\end{tabular}

\subsection{Tampilan Menu Beranda}

Dari menu beranda, perangkat lunak data mining ini terdapat beberapa tombol untuk masuk ke form-form lain. Menu beranda akan tampil pada saat pertama aplikasi dijalankan. 


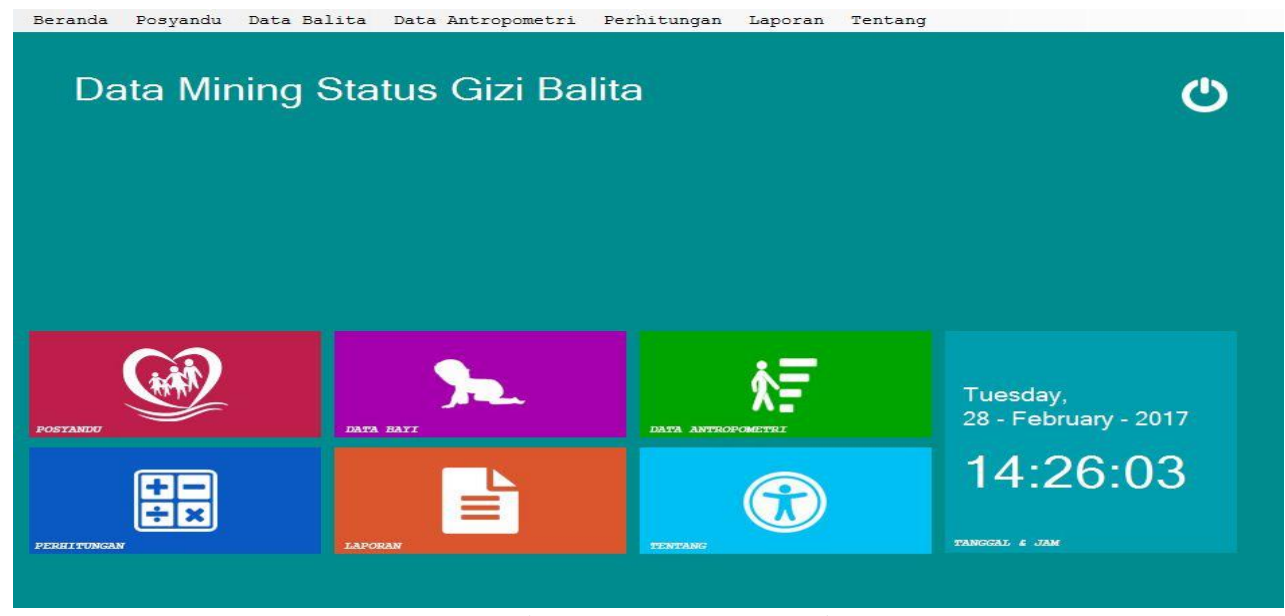

Gambar 1. Menu Beranda

\subsection{Tampilan Menu Posyandu}

Tampilan menu posyandu akan muncul, setelah user menekan tombol Posyandu pada form beranda, form Posyandu berfungsi sebagai form pengolah data posyandu, baik itu menambah data, mengupdate data serta menghapus data posyandu.

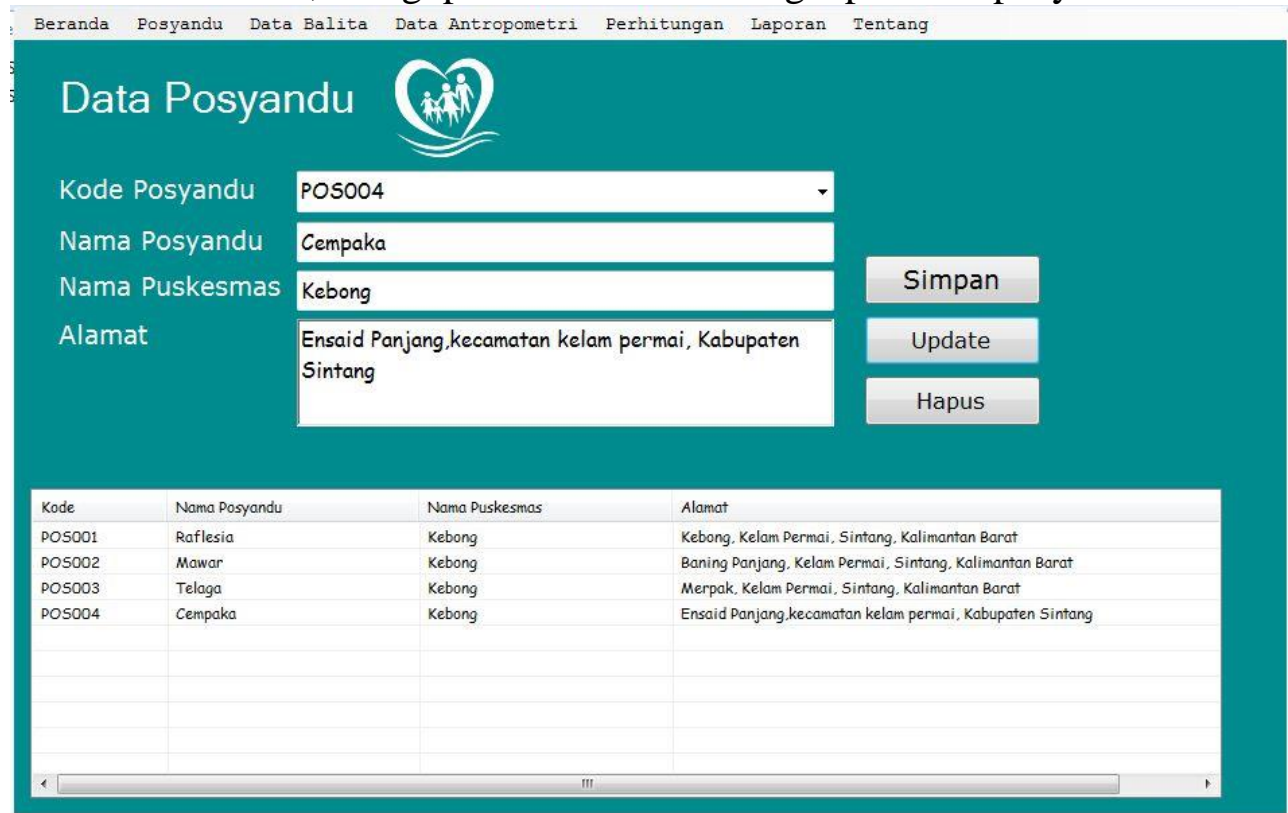

Gambar 2. Tampilan Menu Posyandu

\subsection{Tampilan Menu Balita}

Tampilan menu Balita akan tampil ketika pengguna menekan tombol data bayi/data balita pada form beranda, form ini berfungsi untuk mengolah data balita, baik menyimpan, menambah, serta menghapus data balita. 


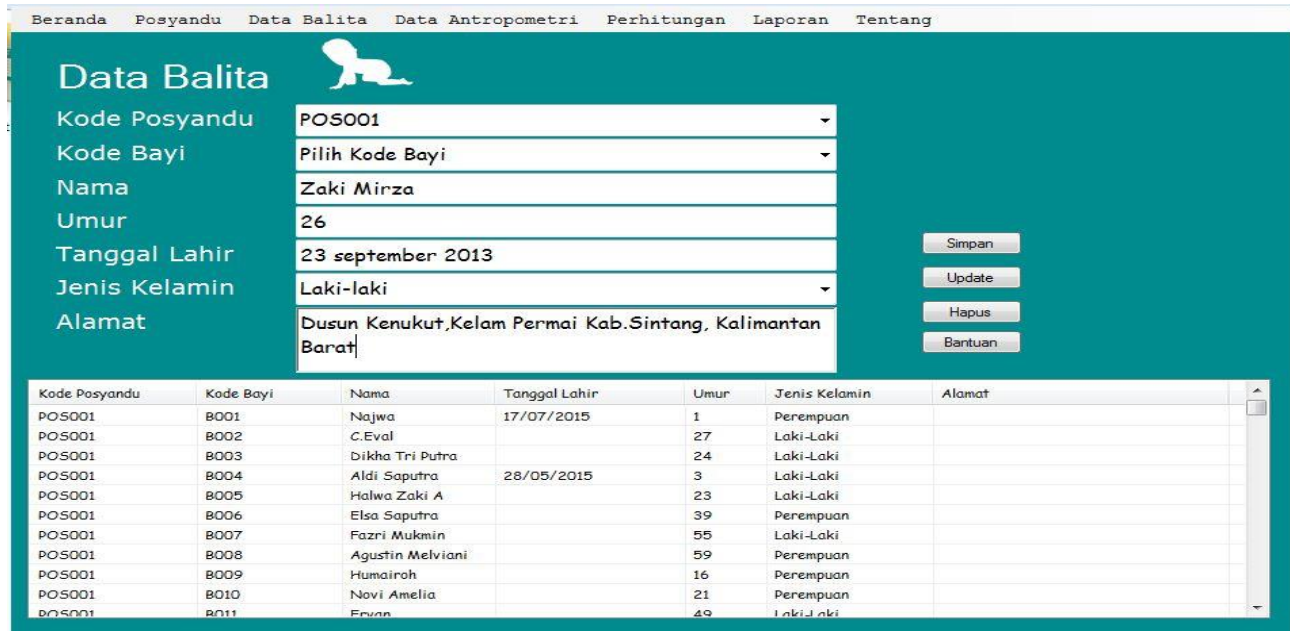

Gambar 3. Tampilan Menu Balita

\subsection{Tampilan Menu Antropometri}

Tampilan menu Antropometri, form ini berfungsi untuk mengolah data Antropometri, mengupdate, serta menghapus data balita.

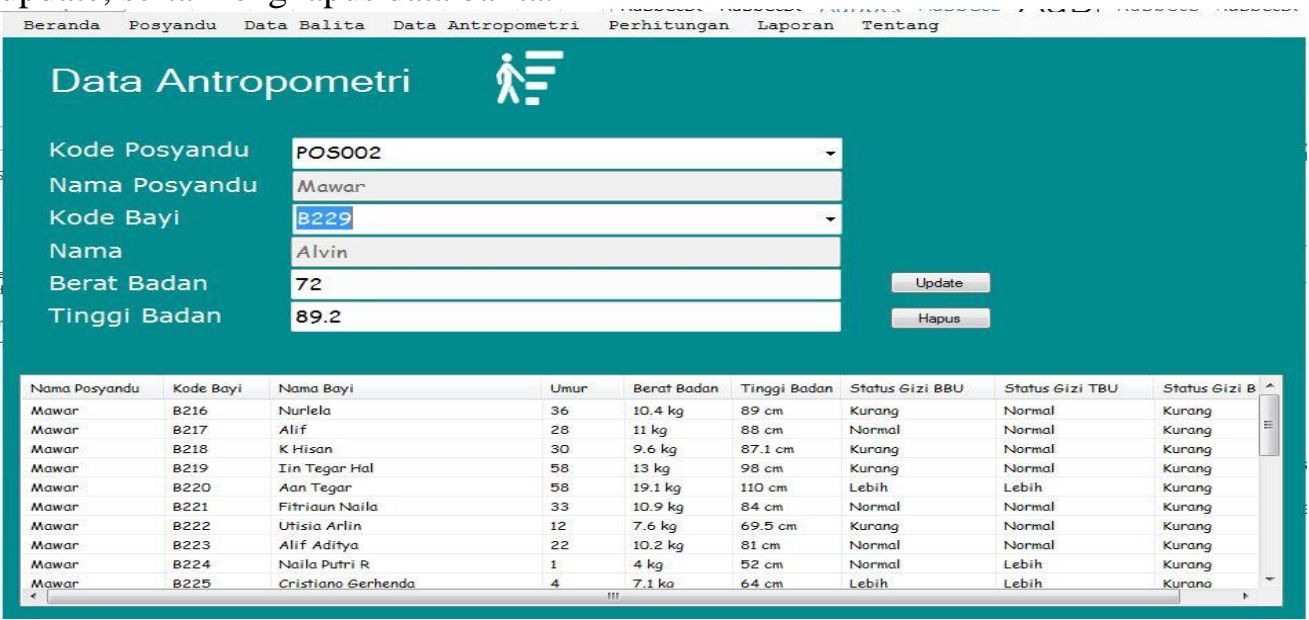

Gambar 4. Tampilan Form Antropometri

\subsection{Tampilan Menu Perhitungan Association Rule}

Tampilan menu Perhitungan Association Rule akan tampil ketika pengguna menekan tombol Perhitungan pada form beranda, form ini berfungsi untuk mencari nilai support dan nilai confidence dari setiap kondisi yang terjadi pada masing masing posyandu.

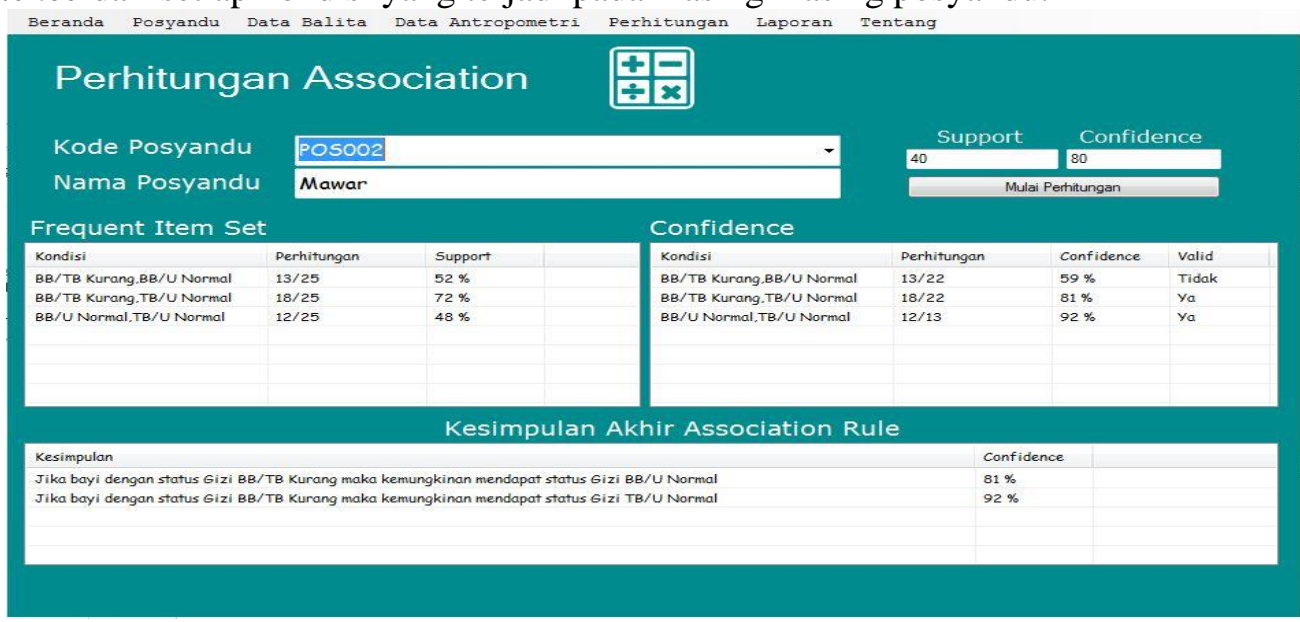


Gambar 5. Tampilan Perhitungan Association Rule

\subsection{Tampilan Menu Cetak Laporan}

Tampilan menu cetak laporan akan tampil ketika pengguna menekan tombol Laporan pada form beranda, dari form ini user dapat langsung mencetak laporan data status gizi balita.

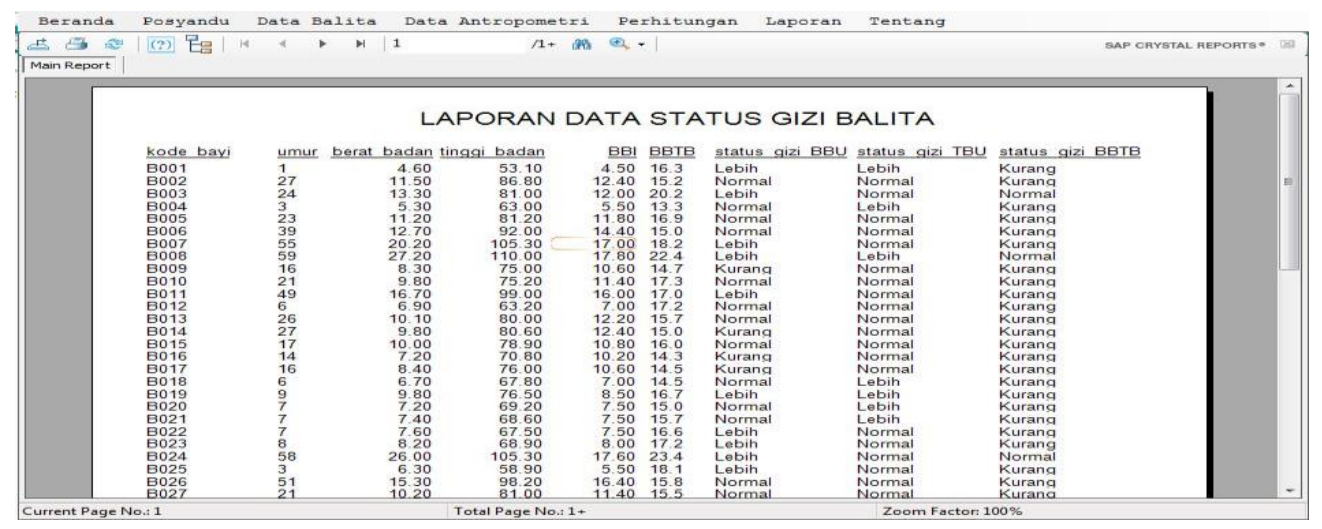

Gambar 6. Tampilan Cetak Laporan

\section{KESIMPULAN}

Setelah melalui proses penyelesaian skripsi yang berjudul "Implementasi Association Rule Mining Dalam Melihat Pola Penentu Keadaan Status Gizi Balita Berdasarkan Teknik Antropometri", penulis menarik kesimpulan bahwa, data yang dimining pada aplikasi data mining ini ialah data status gizi balita berdasarkan teknik antropometri. Kemudian, pada proses perhitungan pencarian nilai support dan confidence pada frequent item set, dilakukan dengan menggunakan algoritma apriori yang terdapat dalam aturan association rule. Pola yang didapat atau kesimpulan akhir dari Association rule bersifat jika-maka.

\section{SARAN}

Penulis ingin memberikan beberapa saran yang mungkin berguna untuk perkembangan lebih lanjut pada Implementasi Association Rule Mining Dalam Melihat Pola Penentu Keadaan Status Gizi Balita Berdasarkan Teknik Antropometri, yaitu Algoritma apriori bukan satusatunya algoritma yang terdapat dalam Association rule, jadi penulis menyarankan kepada pembaca yang ingin mengembangkan aplikasi data mining ini dapat menggunakan algoritma selain apriori, seperti Algoritma FP-Growth dan Algoritma CT-Pro. Dalam perangkat lunak ini, hanya menggunakan data balita, sehingga, jika ingin mengembangkan, gunakan juga data selain balita, seperti data anak- anak, remaja, dewasa, dan lanjut usia. Perangkat lunak ini dapat dikembangkan dengan algoritma lainnya, sehingga mempermudah menyelesaikan masalah dalam bidang steganografi.

\section{UCAPAN TERIMA KASIH}

Penulis mengucapkan terimakasih kepada Tuhan YME, Ketua STMIK Pontianak, Ketua Jurusan Teknik Informatika STMIK Pontianak, Pembimbing Skripsi dan Jurnal, orangtua tercinta, teman dekat dan kerabat yang telah memberi dukungan financial terhadap penelitian ini. 


\section{DAFTAR PUSTAKA}

[1] Sugiyono. 2015. Metode Penelitian Pendidikan Pendekatan Kuantitatif, Kualitatif, dan R \& D. Alfabeta, Bandung

[2] Ghufron, A. (2013). Pendekatan Penelitian dan Pengembangan (R\&D) di Bidang Pendidikan dan Pembelajaran. Handout. Fakultas Ilmu Pendidikan UNY.

[3] Borg, W.R. \& Gall, M.D. Gall. (1989). Educational Research: An Introduction, Fifth Edition. New York: Longman.

[4] Rosa A.S.2013. Rekayasa Perangkat Lunak. Bandung : Informatika Bandung.

[5] Pressman Roger S. 2012. Rekayasa Perangkat Lunak Pendekatan Praktisi (buku satu, edisi Bahasa Indonesia). Yogyakarta : ANDI OFFSET

[6] Utami Ema dan Sukrisno. 2005. 10 Langkah Belajar Logika dan Algoritma, Menggunakan bahasa $\mathrm{C}$ dan $\mathrm{C}++$ di GNU/Linux. Yogyakarta : Andi OFFSET

[7] Turban, E, et al, 2005. Desicion support system and intelligent system, Andi, Yogyakarta

[8] Zakaria dkk. 2007. Perancangan Antarmuka Untuk Interaksi Manusia dan Komputer. Bandung: Informatika Bandung 